Article

\title{
Discovering the Landscape by Cycling: A Geo-Touristic Experience through Italian Badlands
}

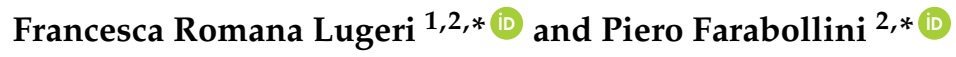 \\ 1 ISPRA Istituto Superiore Protezione e Ricerca Ambientale, Via V. Brancati 48, 00144 Roma, Italy \\ 2 University of Camerino, School of Sciences and Technologies, 62032 Camerino, Italy \\ * Correspondence: francesca.lugeri@unicam.it (F.R.L.); piero.farabollini@unicam.it (P.F.)
}

Received: 18 June 2018; Accepted: 2 August 2018; Published: 4 August 2018

\begin{abstract}
Today, more than ever, it is necessary to adopt an innovative approach to studying and educating the public about territorial sciences. The complex link connecting Earth and society has to be rediscovered, by raising awareness about environmental balances, resources, and risks. The best way, scientifically and culturally, to tackle the problem of sustainable development, is to adopt a methodological approach that includes the fundamental elements of communication, public education and training. Geotourism is a modern and powerful way of informing the general public about geological sciences. Landscape ecology offers new approaches in the field of scientific research, while on the socio-political front, the European Landscape Convention ratifies its essential functions on the cultural, ecological, environmental and social levels. Geographical information system (GIS) technology provides us with powerful communicative tools, suitable for creative and flexible use. We will examine the geo-touristic potential of the "Calanchi" (Badlands) areas in Basilicata region, particularly significant since it is representative of the socio-environmental balance of the territory. An original integration between the landscape, cycling and tourism offers new perspectives on the local economy.
\end{abstract}

Keywords: landscape; society; cycling; communication; geotourism

\section{Introduction}

Italy is a country that, thanks to its morphological configuration and its geographical position, offers an extraordinary richness of different landscapes. Each one of these landscapes is the result of the physical, biotic, and anthropic dynamics interacting in space and time. However, the variety and the beauty of the Italian physiographic structure are signs of extreme vulnerability.

The places we are going to focus on are located in Basilicata, a region in the South of Italy. The charm of Basilicata is evoked by a series of images, light, and shadows, such as those that outline the landscape that the region offers to the observer's gaze. The landscape, in some parts, seems extra-terrestrial; the clayey hills with the badlands, locally called "calanchi", evoke lunar landscapes.

This work describes a study experience dedicated to an Italian region, Basilicata, which, by its nature and culture, offers a stimulating opportunity to enhance local geoheritage by developing a special kind of "cycling geotourism". In harmony with the European Landscape Convention [1], the work is based on the belief that the landscape itself is a common good. Its focus is how to involve society in a responsible interaction with the environment. To meet this aim, a strategic key is communication, with the widest possible audience, of some scientific concepts that can explain what the landscape is in a simple (not simplified) way, why it reveals multiple shapes, how it is evolving, which kind of resources it can offer us, and which kind of hazards it could trigger.

The first part of the paper gives an overview of the geomorphological settings of the area. Then, after briefly analyzing the concepts of geosites and geotourism as tools with which to respectively 
recognize and enhance the landscape's geological resources, we move to the role of the geothematic maps and geographical information system (GIS) in broadly communicating scientific information. The final section is devoted to describing how we have used the experience of cycling within scientific communication aimed at making the landscape more understandable to the public.

The principles of landscape ecology inform the proposed work: The holistic approach has provided the researchers with a concrete point of view from which to interpret landscape in a systemic way. At the same time, it allows the communicator to give the public a complete vision of a complex system in a clear representative framework.

\subsection{Overview of the Area}

From a geomorphological point of view, the area of study is located in the units of the Plio-Calabrian marine cycle. The morphological features here are mostly determined by the hydrographic system, represented mainly, from north to south by the Bradano, Basento, Cavone, Agri, and Sinni rivers-which flow in subparallel valleys with Apennine direction. The tectonic structure of the Bradanic Foredeep [2] characterizes the geological settings of the north-east area of the region.

The hills are elongated in the Apennine direction and are generally gently modeled where clay soils emerge; on the contrary, they are slightly steeper in the areas where the more resistant formations' components form outcrops (conglomerates and sands) [2]. These formations give rise to plateaus that can be large, or limited in narrow bands and small residual nuclei often circumscribed by steep morphological jumps in correspondence to the terrains made of more erodible formations. The medium valleys of the main river courses are characterized by the presence of landslides, whose distribution is a function of the lithological nature of the land and the acclivity of the slopes. The maximum diffusion of these phenomena is in the Basento valley, with the resulting verticalization of the slopes along the right side of this river. The morphology of the slopes comes from the action of gravitational movements, both quiescent and in progress. The landslide phenomena, considered as rapid manifestations of slope modeling, occur in the study area with rotational movements, often evolved as mudflows [3]. Rotational landslides with surfaces that separate the altered clay blanket from that on the "calanchive" gully slopes are observable. The dominant morphologies are precisely the "calanchive" ones, observable in various forms and states of evolution.

\section{2. "Calanchi" Landscape}

The area we are proposing for an improved geotouristic use corresponds to about one third (about $10,000 \mathrm{~km}^{2}$ ) of the regional extension of Basilicata, with particular emphasis on the hilly morphologic settings of the province of Matera. The manifestations of the phenomenon can be seen in the different stages of evolution; the morphological variety and the extension of the phenomenon give rise to many endemic phytocenoses, typical features of the territory [4]. The Mediterranean climate favors the genesis of these morphologies, defined as, "Mediterranean inland hills". The characteristic morphologies of the area are the "calanchive" fronts, developed along the supporting slopes. At the base of these morphotypes lie small rounded protrusions as a transition to the "biancane" consisting of a dense embryonic network, developing radially.

In this paper we are going to focus on a specific area, between Montalbano Jonico and Pisticci, where we have realized some activities for social involvement in knowledge about the landscape and for better (sustainable) development. It is worth mentioning that in the Montalbano Jonico badlands, a section has been identified by GSSP (Global Stratigraphic Section and Point) as an "ideal section" of the Middle Pleistocene Subseries.

As already mentioned, the "calanchive" orography sets on the clayey soils, mainly attributable to the Subappenninic Clays along with the south facing, anti-dip slopes, at altitudes between $150 \mathrm{~m}$ and $400 \mathrm{~m}$ asl. The "calanchi" are therefore shapes of erosion that mold those anti-dip slopes which are steep and resistant to the deterioration of mass movements, thus subject to linear erosion [5]. 
According to some geologists, the microclimatic conditions of the slopes are decisive: Exposure to the south promotes hydro-meteoric erosion due to the accentuated temperature variations [6]. The climate is one of the factors that determines and conditions the genesis and development of the gullies. The area of study is characterized by a typically Mediterranean climate and classifiable as an internal hilly Mediterranean area. The dry period starts in mid-May and ends in late September. The average temperature exceeds $10^{\circ} \mathrm{C}$ for eight months of the year; while the averages of the dry period vary between $21.6^{\circ} \mathrm{C}$ and $24^{\circ} \mathrm{C}$. The average annual temperature is $14.2^{\circ} \mathrm{C}$, the average annual precipitation is $723 \mathrm{~mm}$. The studies developed in recent years on desertification have brought attention to the "calanchive" forms, encouraging new research on the processes of genesis and evolution of desertification. The morphology is the result of the alteration active on the slopes, after the coverage's alteration involvement in mass movements (due to meteoric events of particular importance). This denudation favors the erosive process which is at the origin of the particular geometry of the studied forms [7,8]. The southern exposure, the climatic and meteoric setting [9] and the predominantly clayey nature of the terrain, the steepness and the arrangement of the anti-dip slope, favor the formation of the "calanchi," defined as forms of fast linear erosion. During the summer, the heat causes the withdrawal of some of the clay minerals that make up the outcropping lithologies. In the wet season, instead, the clay minerals tend to swell when they combine with water molecules. The alternation between these physical behaviors favors the formation of cracks, in which rainwater infiltrates, causing erosion.

The lithological-structural characteristics and the microclimatic conditions linked to exposure [10] control the genesis and distribution of the gullies, while the anthropic factors, mainly deforestation, have a direct influence on the rapidity of the development of the gullies network. The environment is characterized by high energy, and thus is continually changing, due to the rapid hydrometric erosive action these forms have a short life. At the base of such shaped slopes are the so-called "biancane," characterized by a dense hydrographic network with radial development; small roundish shaped reliefs enliven the zone of transition towards the valley. The powerful erosive action on the surface of a "biancana" is mostly due to the mechanical action of the rain and the dispersive behavior of the clays. The shape of the "biancane" indicate their maturity [7]. Mature forms are smaller and more symmetrical, with almost equal longitudinal and transverse axes [8]; the younger ones, on the other hand, are characterized by a pronounced asymmetry of the axes and by a considerable difference in height between the upstream and downstream base levels.

The actual "calanchi" are set on the slopes, since acclivity is one of the determining conditions in the genetic phase. The incisions have "V" sections and sub-parallel profiles. Rainwater, once it has reached the base of the altered clay's level, begins to circulate thanks to the combined effects of an erosive/dissolution action, causing a hypogeal sliding (piping) [7]. The effects can be observed on non-vegetated clayey slopes, on which the original surface emerges, and the tunnels are developing along the contact surface between the altered clay. The kinetic energy connected to the impact of water drops on clayey soil causes the formation of "popcorn" surfaces (micro-reliefs on clays and colluvial deposits) and small earth pyramids protected at the summit by fragments of fossils and small pebbles. The continual erosion of the trench ditches over time creates very thin "knife-like" ridges that characterize an amazing lunar landscape. This phenomenon is common in slightly silty soils (Figure 1). 


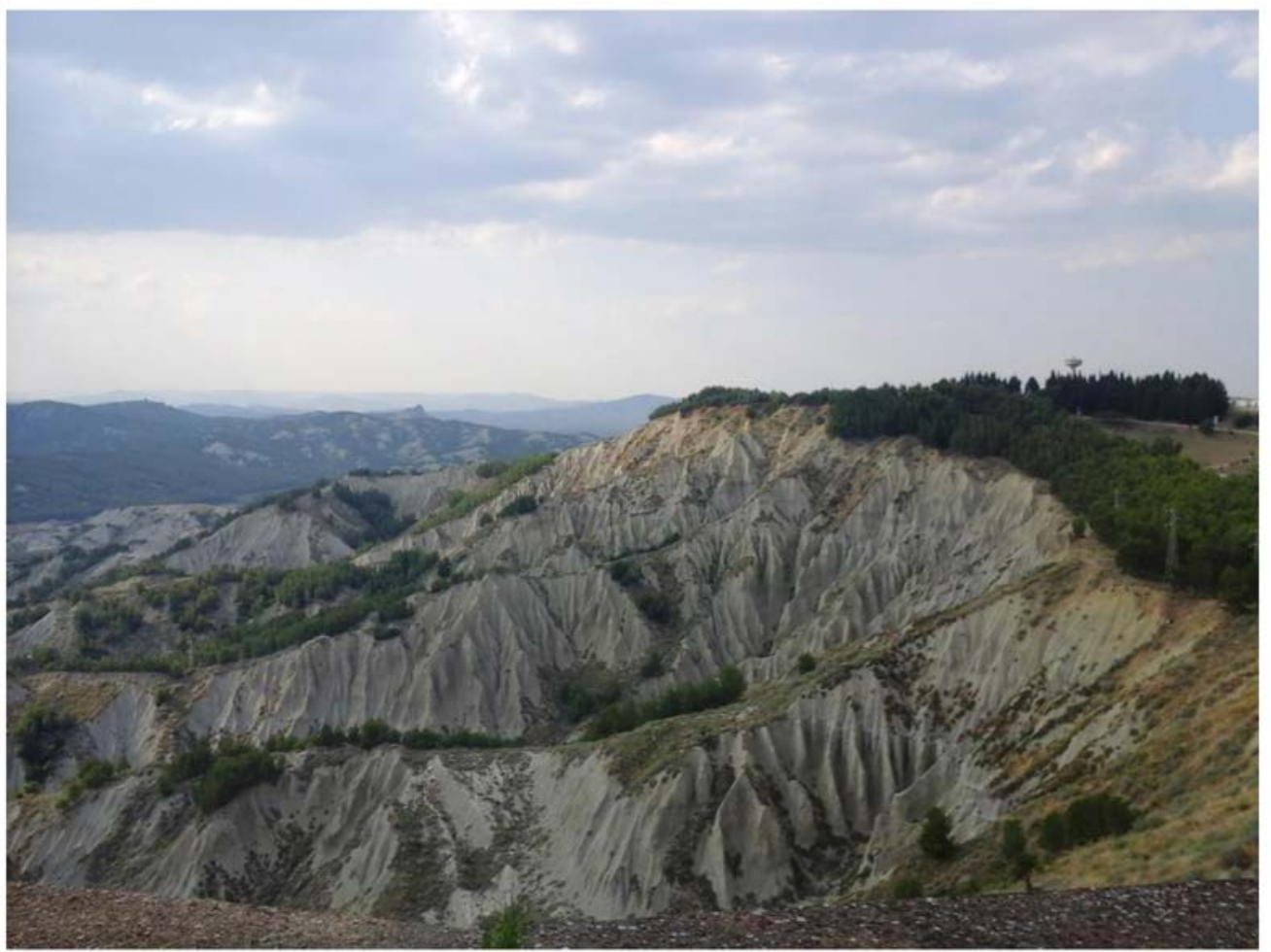

Figure 1. Calanchi in Montalbano Jonico, Basilicata, Italy.

\subsection{Nature and Culture in Basilicata}

"Enchanting colors, white clays, small patches of green, scattered here and there" is how Carlo Levi, the Italian writer, describes Basilicata while in exile there in 1935 [11]. However, the deep meaning of this region can also be found in the hardships and its "history outside of history", as Levi defines the path of a people and civilization that are still little recognized. A symbol of an ancient culture is the "Sassi of Matera", an old settlement that demonstrates how to live in the most difficult environmental conditions, a sign of the fusion between place and inhabitants in a sort of architectural ecosystem. New integration with the city, society, environment, makes the "Sassi" again worthy of "representing a monument to rock habitat engineering, a brilliant form of settlement marked by refined relational systems typical of Byzantine culture, a precursor of the western model of the city" [12]. Matera, United Nations Educational, Scientific and Cultural Organization (UNESCO) World Heritage Site, will be European Capital of Culture in 2019.

Carlo Levi also writes about the "Lucania that is within each one of us" as "vital force ready to become form, life, institutions", the "immobile world of closed, infinite possibilities" [11] of a region and an ancient citizenry, custodian of its own culture and capable of interacting in a community spirit (Gemeinschaft), with a hostile natural environment. Basilicata is surprising for the absoluteness of the forms that characterize its landscape, transforming itself from arid areas, with badlands' geometries and designs, to a more familiar Mediterranean expression. Environmental policies have fostered the protection of some areas, even if (as with the whole of Italy) the harmonic balance and the optimization of economic potentials, are still far from being accomplished.

The identity of the territory is a fascinating combination of morphological, natural and anthropic elements: Natural beauties, climate, food and wine, and archeology. The link between Lucania and its people is a remarkable resource, which, if used in the right way with the most appropriate tools, could promote a good and suitable sustainable development.

Carlo Levi interprets Lucania from a paradoxically ideal point of view: In his forced residence, in exile, he finds and gives us the key to understanding a territory that visitors must discover slowly 
and deeply. Today Basilicata tries to reopen those "closed, infinite possibilities" through its policies of regional promotion.

The emigration and the "abandonment syndrome" that impoverished a region that in 1860 had more inhabitants than today, can be countered through the rediscovery of the deep stratification of the Lucan culture.

Until now, tourism in this region has been concentrated on the spectacular city of Matera. Further sites have been selected according to historical significance (Metaponto), the sandy coastal lines, food and wine, and even movie tourism, as well as for other kinds of attraction. One of these, the "Volo dell'angelo" (angel flight), gives the visitors a special experience of flying thanks to a steel cable suspended above the Lucanian Dolomites (which, despite their name, are made of quartz sandstone).

All of these themes offer the chance to develop a new style of tourism, that should be named 'geolandscape tourism', where the 'geo' prefix denotes our planet, and 'landscape' encompasses the environment, its features, its biologic, geologic, anthropic components, integrated into a spatial/temporal scale.

\subsection{Geosites and Geotopes}

The physical characteristics of the landscape, the substratum on which the biotic component lives and with which it interacts, deserve appropriate consideration, for scientific and management reasons. Some researchers have identified geosites as geodiversity indicators, understood as geological specificity. However, it is possible to describe geosites, according to the most common definition, as elements, zones, or places of geological-geomorphological interest worthy of conservation and protection. In this sense, geosites become emerging elements of the geological diversity existing in a given context [13-15].

Very often the term geotope is used in place of the term geosite generating confusion, or at least doubts. According to the definition of geotope, coined by the German school, a geotope is a primary element of the landscape (landschaftelement), like the biotope, identifiable as the smallest unit of the Earth's surface, geographically definable, homogeneous by characteristics and structure. In this sense, the parallelism between geodiversity and biodiversity is justified because, even if on different scales, endogenous and exogenous processes, and rocks, as elements of landscape formation, influence the evolution of environments and biological diversity and are the basis of the spatiotemporal development of a region [16-18]. The relationships between the components of the landscape and the environment are very close. The relationships between causes and effects of the phenomena concerning the physical part of the territory, and the biological one have a logic of reciprocal reciprocity [19], with a view to studying environmental diversity understood as integration between geodiversity and biodiversity. By recent definitions agreed in the nationally and internationally, the term "geotopes" refers to those geological manifestations, the physical elements of the territory or the singularities of the landscape that manifest a scientific value, as an expression and testimony of the processes that have originated and modeled the planet Earth. At the same time, geotopes have additional attributes of aesthetic, naturalistic, cultural, historical, tourism and educational values. According to Wimbledon's definition of geosites, applied in the GEOSITES Project of IUGS (International Union Geological Sciences), a geosite can be any location, area, or territory where it is possible to define a geological or geomorphological interest for conservation [20].

In any case, the desire to guarantee the conservation of places of high geological interest arises with the need to ensure future generations a conscious and enjoyable use of the landscape in all its configurations. While the Italian Framework Law on Protected Areas (394/1991) [21] is based on protection and management of the same, it also provides for the conservation of geological singularities, paleontological formations, scenic and panoramic values, natural processes, hydraulic and hydrogeological balances.

The development of awareness in Italy that the landscape is a collective asset is complicated by difficulties such as the fact that environmental education is disadvantaged, causing deficiencies 
and fragmentation in the knowledge of nature and in the perception of the importance of geological monuments.

The conservation of geosites cannot overlook an adequate and complete knowledge of their existence and distribution. For this purpose, a documented, widespread and coordinated census work is essential. Instruments suitable for the collection of comparable and reliable data, destined for a database and a GIS, have been developed at national level, by the Institute for Environmental Protection and Research (ISPRA) [22].

\subsection{Geotourism in Italy}

It is important to start from the main definition of geotourism: It is sustainable tourism with a primary focus on experiencing the Earth's geological features in a way that fosters environmental and cultural understanding, appreciation and conservation, and is locally beneficial [23]. In parallel, it is a synergic form of tourism in which the elements of the landscape and landforms together create a tourist experience that is richer than the sum of parts, appealing to visitors with diverse interests [24,25].

Due to its nature, geological tourism is intrinsically linked to outdoor sports; however, the related opportunities of development have not been taken advantage of yet. These sports include skiing, trekking, climbing, sailing, rafting, diving and of course cycling. Each of these sporting disciplines allows the participants to discover different landscapes and to appreciate from different points of view the components that play a key role in the landscape's features as well as in the sporting experience: Rocks, shapes, morphological settings, climate and vegetation. A question then arises: Why has geotourism not reached mainstream acceptance and success as it should have? Recent studies confirm that the largest part of research on this topic comes from Italy [26]. However, geotourism itself is not particularly developed in our country. Italian ecotourism is more recognized, whereby information and data are standardized, and proposed in a systematic way, referring to disciplines as biology, botany, zoology, even architecture. Geology in particular, and Earth Sciences in general, are relegated to a niche sector, coming to public attention only in the case of disasters. The reason for this is a communication problem. The right way to inform the public about the Earth Sciences demands a new language, one that is able to communicate scientific information in a systemic rather than systematic way. The same systemic approach that guides the field of study on the Landscape, thanks to the paradigm of landscape ecology.

\section{Materials and Methods}

The abundance of studies on geotourism combined with the low level of development in Italy testify a lack of integration between these two essential components of a complete local geo-enhancement project. A holistic approach is the one that guarantees a complete vision of the landscape in both research and dissemination to the public.

\subsection{Theoretical Basis: Landscape Ecology and Environmental Diversity}

The paradigm of landscape ecology is primarily based on the relationship between structure and function. In general terms, each studied landscape has its own characteristics [27]:

- $\quad$ Structural: Physical form and specific spatial organization

- $\quad$ Functional: Relationships between biotic and abiotic elements

- Dynamic: Evolution of the structure

The second principle is that the universe is: "not homogeneous ... (it is) dynamic, multiscale and hierarchically organized" [28].

The landscape is the result of processes: i.e., the landscape is the result of the interaction between physical, biotic, and anthropic components acting in different spatial/temporal scales [29]. 
The extreme variety of the biotic and abiotic components that forge our planet and the complex functional correlations that make them mutually dependent and inseparable are summarized in the definition of "environmental diversity".

Let us start from life forms: In their variety they are considered, and from a biodiversity perspective, they are viewed as a "variety of ecosystems, which include both the communities of the organisms present in their particular habitats and the physical conditions under which they live" [30].

The shapes of the landscape, in turn, reflect those geologic phenomena that molded the Earth's surface; rocks of different origin evolved in different forms. If we consider the various forms that characterize the different regions, the nature of vegetation, the distribution of living beings, it is clear that all these are closely linked by geological causes. Environmental diversity understood as integration between geodiversity and biodiversity, can, therefore, be considered in its components and decomposed into hierarchical levels of organization; its preservation must necessarily refer to integrated studies on living organisms, on habitats and ecosystems, and on geological heritage [31,32]. In recent years, the topic of knowledge and enhancement of our geological heritage has produced a scientific debate at the national and European level that has provided numerous indications regarding methods and criteria for the census, knowledge, and enhancement of sites of geological interest (geosites) [33-35].

The landscape ecology paradigm is the conceptual basis of a mapping project realized in Italy, aimed at representing the Italian landscapes as well as at evaluating their ecological value and vulnerability. The concept of environmental diversity plays a key role in the assessment procedure as an indicator of high levels of quality, analyzing biodiversity and geodiversity in an integrated concept, in order to perform a synthetic index that encompasses the complexity of the systemic functions performed within the landscape itself $[22,35,36]$.

\subsection{Tools in Studying and Communicating Landscape}

The "Map of Nature" [37] is based on two reference scales: 1:250,000 and 1:50,000.

The multi-scale factor makes the analysis significant of those processes that keep the systemic units' functions efficient. The study has identified for each scale the territorial reference elements, the so-called "basic polygons": Every information or data, refer to it. Even though it plays a reference role, the set of base polygons at a given scale represents only one of the different layers of data contained in the GIS, which is capable of managing multi-scalar information. The combination of the information extractable from the data at the different scales, compatible with the geometric accuracy intrinsic both to the data input and processed outputs, provides a wide range of tools to the decision-maker, or more generally, to the end user (Figure 2).

The map and related tables converted into digital form constitute a database that is part of a GIS. The description of the environmental units has two steps: A short description in the table of the attributes of the polygon linked to the map, and then a more detailed one to be visualized by the essential tools in the customized "project" dedicated to displaying the GIS. In this paper we will refer to the synthetic scale 1:250,000 whose emerging phenomena are specific to the landscape, particularly to geomorphological settings.

Thanks to its characteristics, the Italian Landscape Units Map (one of the "Map of Nature" project's products), becomes an effective tool in communicating scientific concept about the landscape, to a wide public. 


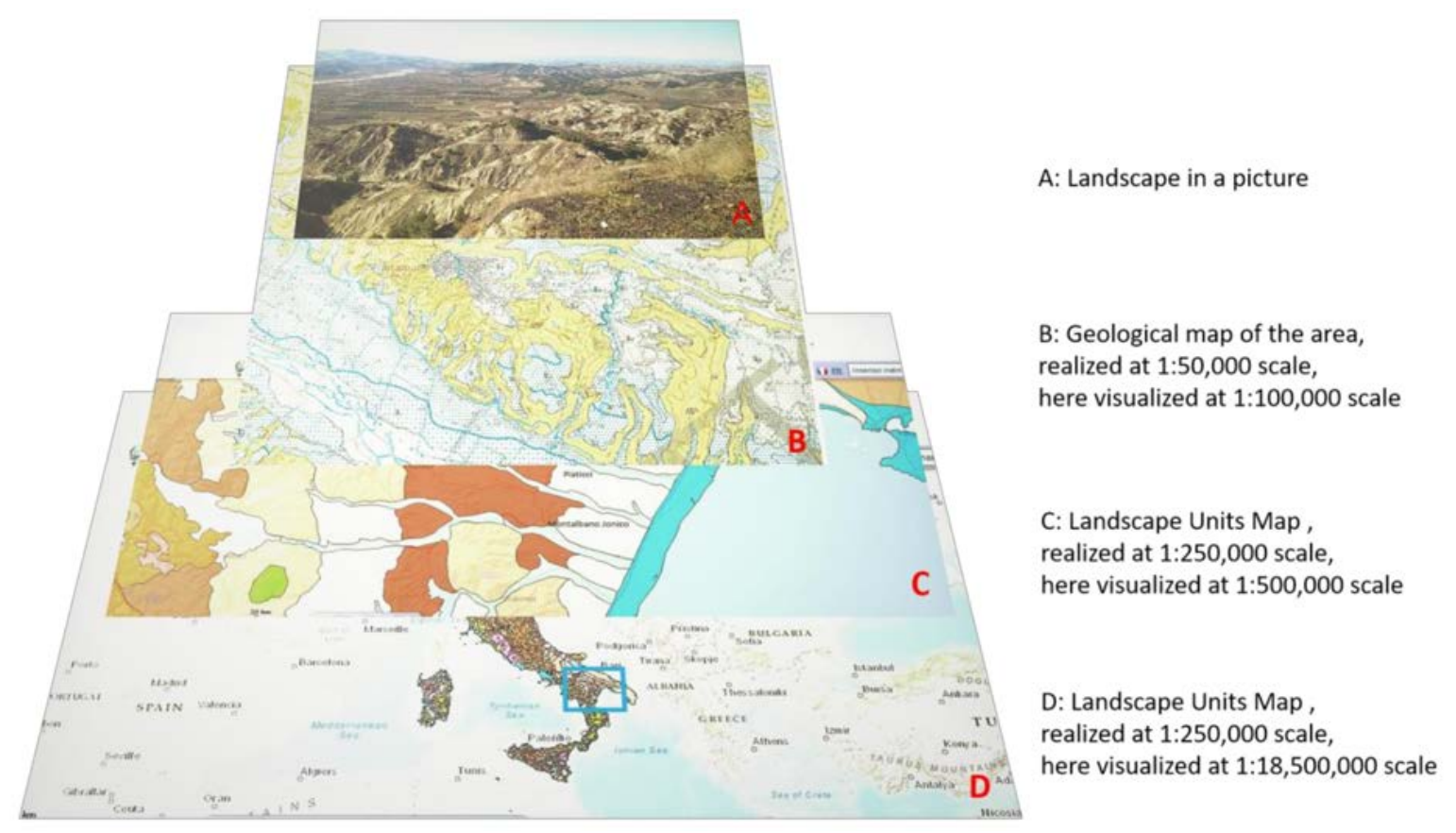

Figure 2. A schematic representation of the multiscale approach in the case study.

\subsection{Landscape Units}

"Shape is synthesis" (Aristotle).

In the Italian territory, 37 types of landscape have been identified. The typologies have been defined by a series of criteria which derive from the synthetic observation of the main characteristics that inform the landscape structure on the regional scale. The landscape, at this scale, is mainly characterized by the morphological structure, in turn linked to the lithology of the substrate. It is also opportune to associate the relationship that a landscape has with the surrounding landscapes [37]. Landscape units are well-defined and geographically characterized portions of territory that are mapped, using the typological classification of Italian landscapes, developed to recognize and identify the surface of the country, and to analyze and evaluate how they are evolving. There are more than 2000 Italian landscape units (Figure 3). Each of them belongs to a specific type, and has been described in a particular way using the same morphological, lithological, hydrographic and coverage elements of the soil, as defined in the classification of the types, to highlight the territorial specificities. Regarding the Basilicata region, the landscape is complex and varied, and using the "Carta della Natura" methodology, the landscape units highlighted in the figure have been identified, belonging to the types "Clayey Hills" and "Terrigenous Hills" (Figure 4).

The landscape units' GIS provides a clear display and a complete description of the selected area (Figure 5). The GIS architecture is designed for multipurpose use, for territorial planning as well as for educational programs. The Italian Landscape Units Map was the starting point in the creation of a smart-app, dedicated to the landscape-the LandscApp, realized by ISPRA as a prototype. This social tool makes thematic maps and scientific information widely available in an understandable way. The possibility of visualizing an interpretive representation of reality in a spectacular way (3D modelling, animation etc.) makes the GIS a particularly engaging tool and thus an effective one for educational use [38-40].

Referring to the case study, the calanchi area between Montalbano Jonico and Pisticci, is included in the landscape type "Clayey hills". The type's characteristics are listed in Table 1. 
Table 1. Information related to the landscape type where the "Calanchi" are located.

\begin{tabular}{ll}
\hline $\begin{array}{l}\text { Clayey Hills } \\
\text { Synthetic Description }\end{array}$ & $\begin{array}{l}\text { hilly reliefs, mainly clayey, with rounded tabular peaks-occasionally crests—and with slopes } \\
\text { with generally low to medium acclivity }\end{array}$ \\
\hline Altitude & $600-700 \mathrm{~m}$ \\
\hline Roughness & Low to medium \\
\hline Lithology & Clay, silt, sand, conglomerates. Secondarily gravel, vulcanites, travertines \\
\hline Hydrography & Dendritical and sub-dendritical, parallel, trellis. \\
\hline $\begin{array}{l}\text { Morphological } \\
\text { Components }\end{array}$ & $\begin{array}{l}\text { Morphological: Rounded peaks, tubular and/or crested, slopes with a generally low to medium } \\
\text { acclivity, "V" shaped or flat-bottomed valleys, widespread phenomena of slope instability and } \\
\text { accelerated erosion, "calanchi", "biancane", ridges. Secondarily: Peaked plateaus, travertine } \\
\text { plateaus, sandstone or conglomerate, terraces, plains and alluvial conoids. }\end{array}$ \\
\hline Land Cover & Agricultural land, shrub and/or grass vegetation \\
\hline
\end{tabular}

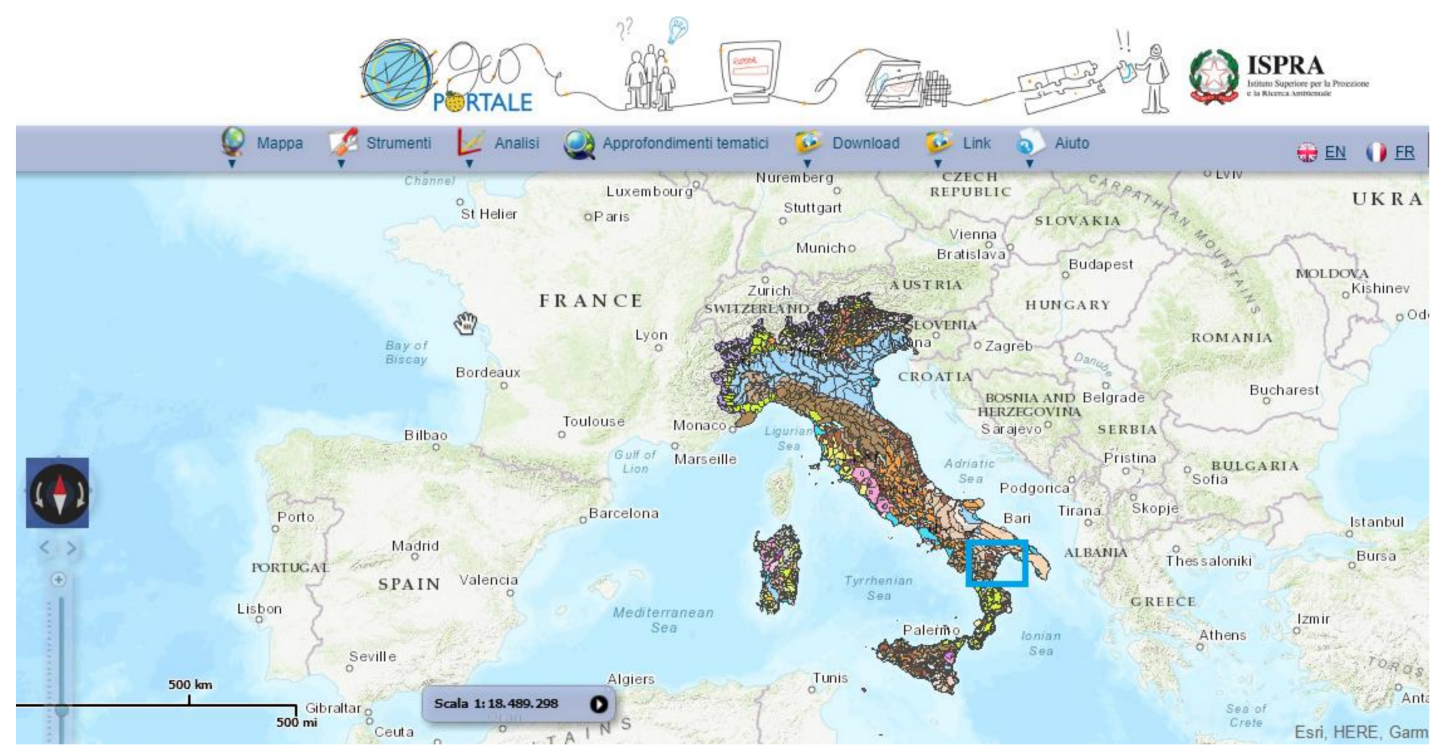

Figure 3. Landscape units map (http://www.geoviewer.isprambiente.it/). In the box, the area of interest.

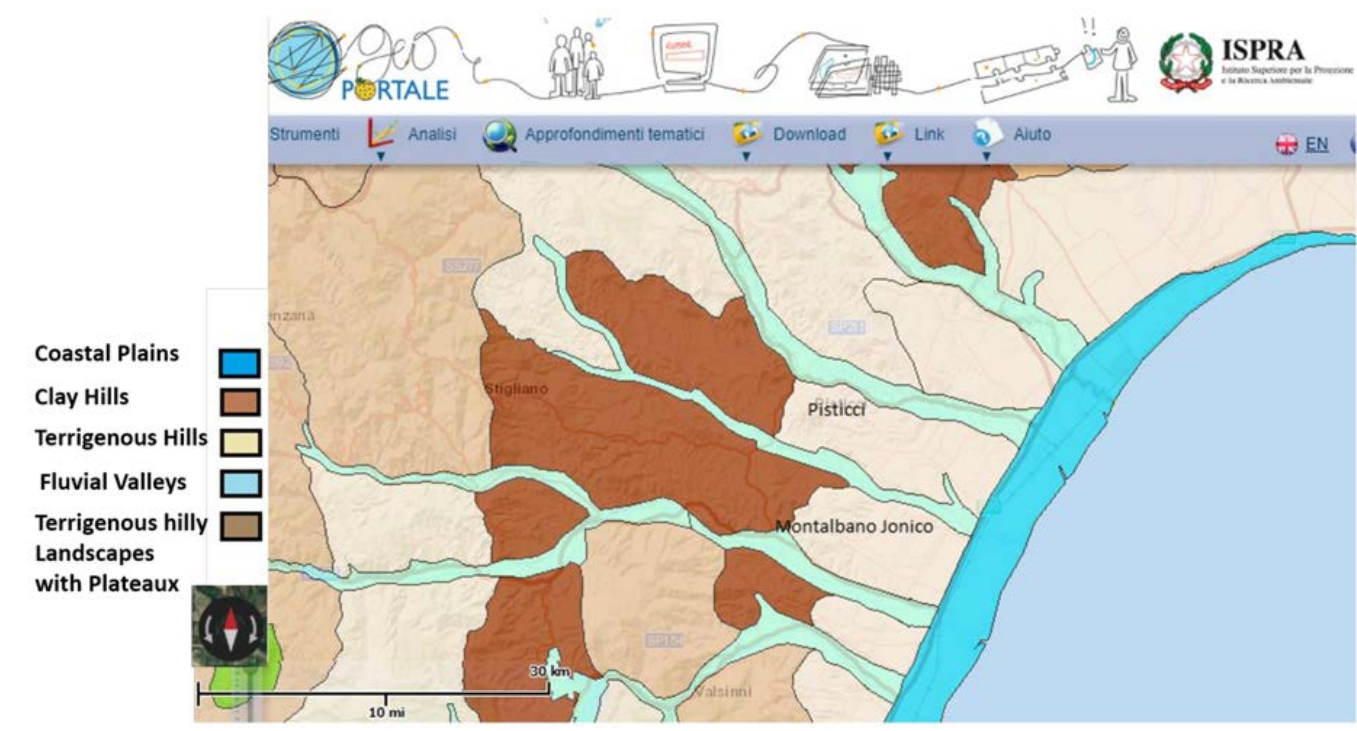

Figure 4. Landscape units of the case study, where are located the calanchive areas, between Montalbano Jonico and Pisticci. 


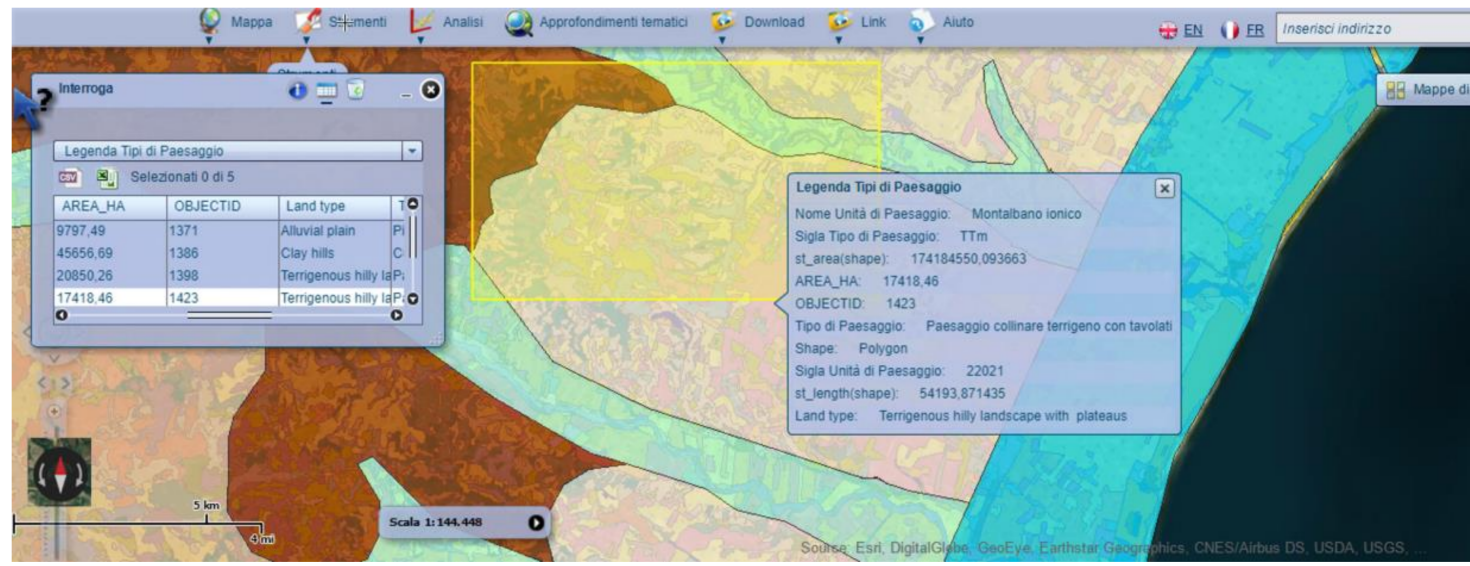

Figure 5. Image and information of the case study as displayed by the geographical information system (GIS) Carta della Natura (http:/ / www.geoviewer.isprambiente.it/).

\section{Results and Discussion}

\subsection{The Calanchi Bike Marathon}

The formations of "calanchi", due to their extension on the regional territory, their morphological variation, their representativeness of the evolution, as well as for their manifested beauty, can be considered significant morphological elements of the landscape, and thus the "calanchi" area forms a part the Italian geosites' database [22]. However, the regional policies at a national as well as at a local level, have not led to enhancing or raising the profile of the region. Geotourism should have already been developed in the area, considering how worthy it is of particular scientific and touristic attention. How best to enhance these sites? Fortunately, there are some local associations that periodically organize events aimed at involving the local population in visiting and enjoying the geological beauties.

Every year, since 2014, a pool of associations in Montalbano Jonico, organizes a national amateur cycling race. This kind of race represents more than a sport event, and has become a multi-day celebration featuring music, food, and beverages that come from the area where the race takes place. Thanks to cooperation with the local community, particularly with the relatives of Domenico Pozzovivo (a famous professional cyclist), a geologist offers the public a scientific but comprehensible explanation of the geomorphological characteristics of the area where the race takes place, within a social event, both before and after the race.

In initiatives such as this one, the aims are to:

- Explain the Italian territory through the landscape, referring to it as a powerful instrument of social recognition of a common heritage. The European Landscape Convention provides legal and ethical references for the implementation of such experiences and proposals [1].

- $\quad$ Reach a wide and varied audience, in particular those target groups that are less sensitized to environmental issues [41-44].

- $\quad$ Highlight the bond between nature and culture [45].

- $\quad$ Promote intergenerational communication to involve the entire society [45].

- Provide "unexpected" information through unconventional channels [45].

- Invite leading figures to be actively involved (mainly from the world of sport and show business) [45].

- Include communication in appealing contexts, such as outdoor sports (significant sports events, cycling, skiing, sailing, trekking) [44-46]. 
As a matter of fact, the use of topics more appealing to the broad public as vectors of ecological concepts is a successful strategy when attempting at connecting society and environment. Therefore, it is very important to choose relevant places that are unique in representing the link between nature and culture, featuring high environmental value and vulnerability. These places are distributed on the geographical context of the Italian peninsula, representing different environmental problems typical of the country. The locations should be chosen both for their physiographic structure, for the relation with society through time, and for the particular role they assume in the public events.

\subsection{Audience and Public Approval}

The Calanchi Bike Marathon (Figures 6 and 7), has provided the opportunity to integrate the GeoloGiro experience (due to a more direct contact with the public). This was aimed at making comprehensible to the general public (and to the athletes) the environmental setting of the landscapes crossed by the cycling race "Giro d'Italia", the most important stage race in Italy. The race is approximately $3500 \mathrm{~km}$ long, includes 21 stages, and held every year in May. Rai Sport (the Italian state TV company), has included in the live programming of each stage the "Anteprima Giro", a short insert dedicated to offering the public a new and intriguing point of view of the landscapes and the sites, linking scientific information to the competitive value of the stage.

The morphology of the territory becomes a key component in the context of the race; scientific information about the geo-morphologic settings of an area is related to cultural news and the local arts and tradition (always profoundly linked to environmental conditions).

During the last edition of both of the Calanchi Marathon (5 May 2018) and the Giro, (Italian stages 8-27 May 2018), a cooperation with a cycling-focused web channel "Repubblica delle Biciclette" (Bikes' Republic), allowed us to disseminate information to the broadest public, reaching encouraging results, thanks to a novel, up-to-date, style of sharing knowledge. In the diagram (Figure 8) the results of such campaign are shown, in terms of the social media audience.

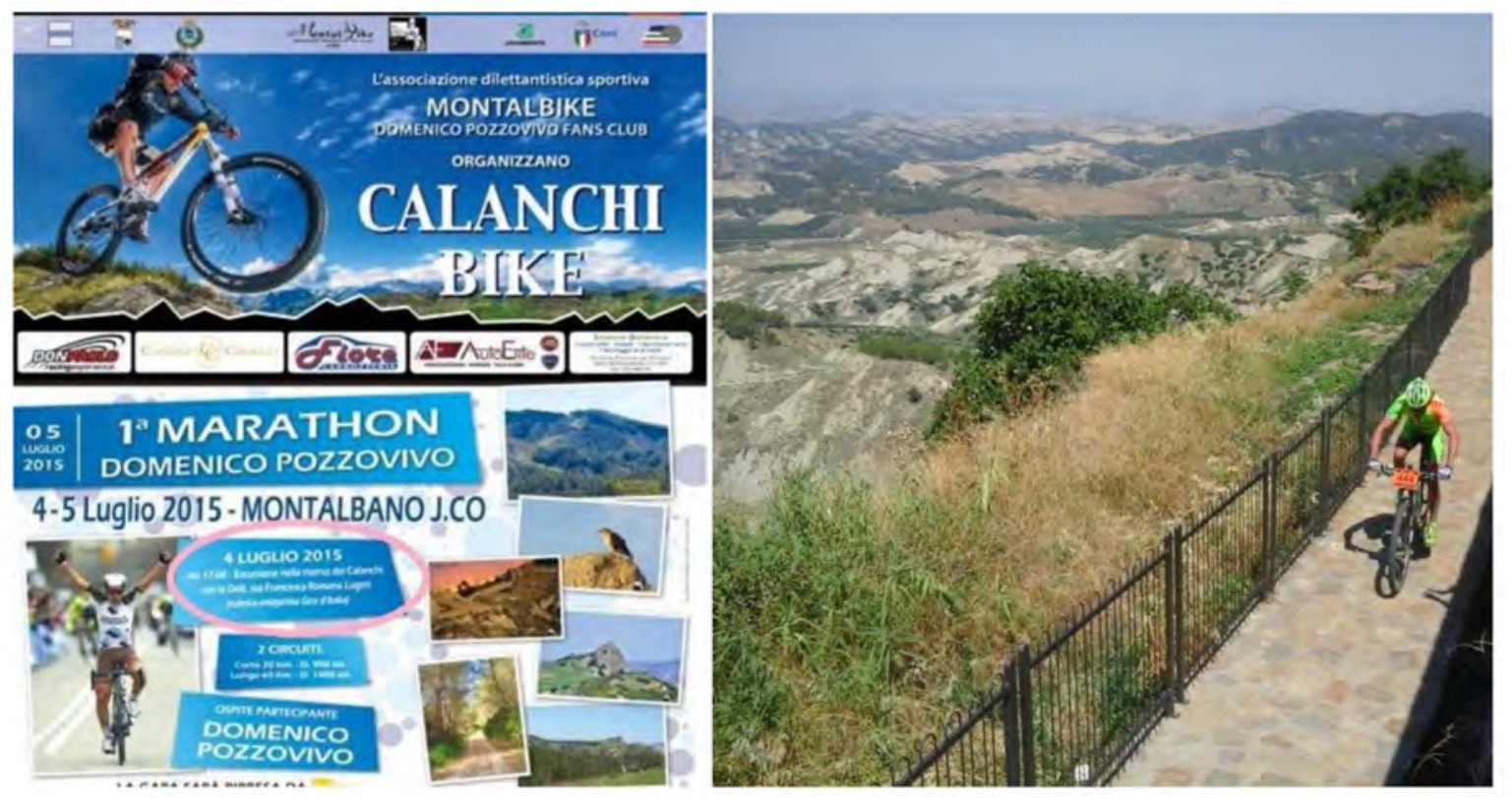

Figure 6. The Calanchi bike marathon. The program included the presence of the geologist (circled in pink). 


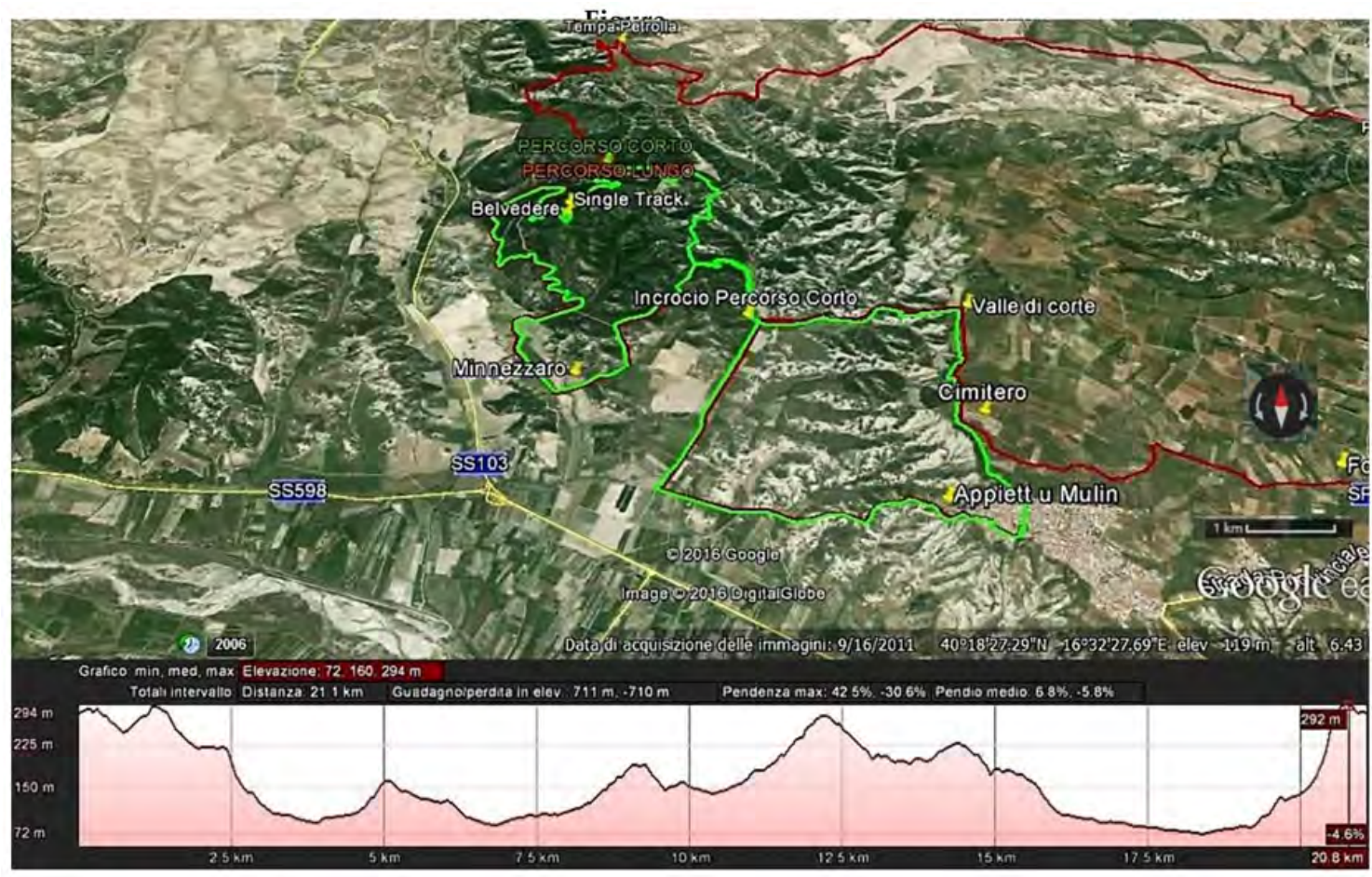

Figure 7. The Calanchi bike marathon track (courtesy of the organizing committee).

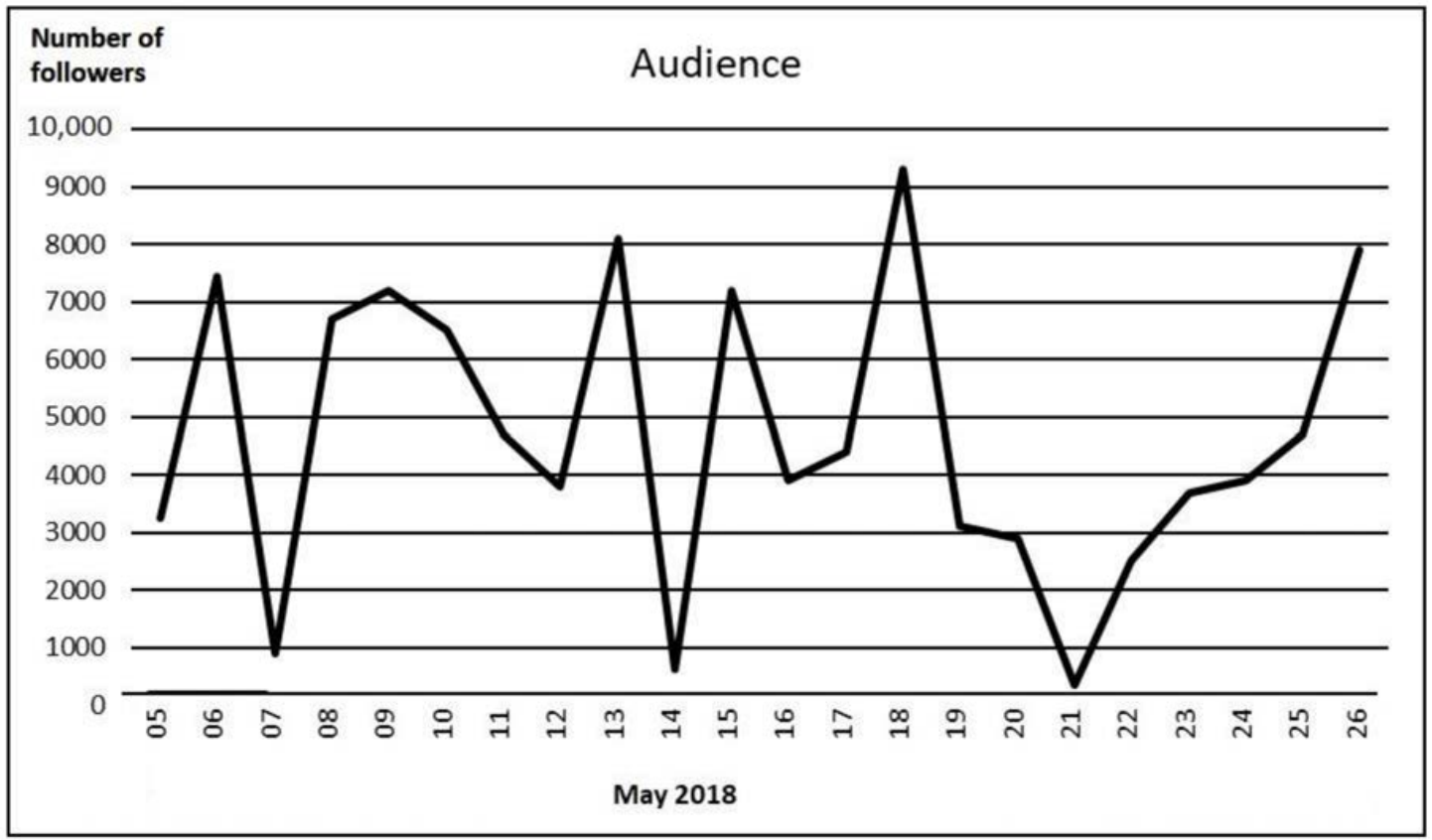

Figure 8. Audience data of the "Repubblica delle Biciclette" social media channel, referring to the geology and cycling events' followers, at the Calanchi bike marathon (May 6) and at the Giro d'Italia special interviews on the geological settings of the stages.

The unique territorial arrangement of the "calanchi" area, give the geologist/communicator a special chance to highlight the binomial risk/resource intrinsic to the landscape. It should be emphasized that the territory of the Basilicata region is exposed to hydrogeological instability, in particular to landslides, due to its physiography and its geographic position. Often the 
causes triggering the occurrence of damaging events are attributable to anthropic interventions inappropriately achieved in unfavorable environmental conditions. In parallel, the beauty of such landscapes should trigger an improvement in local development.

We firmly believe that a new style of communication is urgently needed, especially with the goal of involving those social components not yet interested in the sustainable fruition of geological resources (nor conscious of geological risks) [37,40].

\section{Conclusions}

As already mentioned, the one way towards a complete understanding of the landscape is in studying it by following a holistic approach that integrates all the components of the focused area. Such methodology requires a different point of view (if compared to each of the specific disciplines), and it gets closer to the natural attitude to conscious observation. In this sense, the study of the landscape contrasts with the fragmentation of knowledge; it requires collective action, in which everyone is aware of putting his or her discipline at the service of a cognitive strategy. At the same time, it offers new perspectives on the transmission of knowledge, while opening a dialogue between technicians, decision makers, politicians, and citizens.

We are living in the Anthropocene-an era characterized by technology and virtual reality, where everything is superficial, and is as fragmented as a broken mirror surface. Therefore, it is essential to have an effective way to share knowledge, find educational programs, and communicate. Since the landscape is an object of human perceptions it could become a "medium" to communicate the Earth Sciences to the whole of society; it thus can be considered the result of the interaction of many natural and cultural components, as well as the expression of the geological processes.

Landscapes, if recognized and understood, become part of everyone's cultural heritage. This cognitive process triggers a virtuous circle, which revitalizes the roots linking humankind and environment; it fosters a more creative participation of society in a balanced management of the territory and sustainable development, which constitutes an essential resource in times of crisis. In this sense, a culture oriented to appreciate such resources can be better developed thanks to the discovery of geosites and initiatives in geotourism [47]. However, very often those problems tied to an inadequate understanding of scientific language, require new strategies. How can this kind of tourism become appealing to the general public? What is required is a powerful "communicating vector" such as the beauties, products, and experiences of landscapes. The results of the Calanchi bike marathon and of the GeoloGiro, encourage the use of unconventional ways in disseminating scientific knowledge. In this sense geotourism should become an experimental field in which to perform innovative activities aimed at involving a wide audience, especially those parts of the population not yet reached by scientific communication. As mentioned above, the use of special topics that make sciences more appealing to the audience is essential. Other experimental projects are going on in Italy, based on popular themes-such as television series and movies [45], where the natural scenery is relevant in the plot. The geological origin of the environmental setting of the story, is explained to the public following specific communicative tactics, aimed at making "friendly" the focused scientific topics. A further initiative is devoted to Italian wines and their link to the landscape where the wines are produced: A research line started in Italy by Lucilia Gregori [48], now adopted and performed by "Geologia \&Turismo", an Italian association operating in the field of geotourism.

The role of geotourism is essential for environmental protection, and sustainable development: it can, and must, become a strategic trend, useful in starting social processes aimed at raising awareness and changing the behavior of the general public. The experiences realized until now, form the basis from which to create a trend, involving the broadest possible public, thanks to cooperation between local associations, local administrations, school, and social media. On the other hand, the effect of an increasing number of tourists, albeit educated, visiting those places whose geological beauty is linked to its fragility, must be closely monitored [49]. The delicate balance between the development of tourism and environmental protection can be maintained by knowledge, a shared knowledge. In this 
sense, the importance of restoring and revitalizing the deep roots that bind together nature and culture in Italy is evident. The Basilicata region encompasses most of those factors that enable a region to develop as a dynamic and open cultural area, raising awareness of natural and cultural heritage.

Author Contributions: Conceptualisation, F.R.L. and P.F.; Data curation, F.R.L. and P.F.; Investigation, F.R.L. and P.F.; Methodology, F.R.L. and P.F.; Writing-review \& editing, F.R.L. and P.F.

Funding: This research received no external funding.

Acknowledgments: The authors are grateful to the three anonymous reviewers for their useful suggestions as well as to Nicola Lugeri for the critical reading of the manuscript and Sarah Morgan for reviewing the English text.

Conflicts of Interest: The authors declare no conflict of interest.

\section{References}

1. Council of Europe. European Landscape Convention; European Treaty Series, No. 176; Council of Europe: Strasbourg, France, 2000; pp. 2-4.

2. Boenzi, F.; Radina, B.; Ricchetti, G.; Valduga, A. Note Illustrative Della Carta Geologica d'Italia; Foglio 201 Matera; Servizio Geologico d'Italia: Roma, Italy, 1971.

3. Festa, V.; Sabato, L.; Tropeano, M. 1:5,000 geological map of the Upper Cretaceous intraplatform-basin succession in the "Gravina di Matera" canyon (Apulia Carbonate Platform, Basilicata, southern Italy. Ital. J. Geosci. 2018, 137, 3-15. [CrossRef]

4. Bentivenga, M.; Fascetti, S. Le aree calanchive della Basilicata: Aspetti geomorfologici e geobotanici. Biol. Ital. 1999, 29, 16-24.

5. Azzi, G. I fenomeni dell'erosione nelle Argille Azzurre nel Pliocene nel bacino di Santerno (Emilia Romagna). Bollettino della Società Geogafica Italiana 1912.

6. Passerini, G. La Degradazione Idrometeorica dei Terreni Argillosi Italiani. In Atti I Simposio It; Agrochimica: Pisa, Italy, 1957.

7. Alexander, D.E. Difference between calanchi and biancane badlands in Italy. In Badland Geomorphology and Piping; Bryan, R., Yair, A., Eds.; Geo books: Norwhich, UK, 1982; pp. 71-88.

8. Vittorini, S. Ruscellamento, deflusso ipodermico ed erosione nelle argille plastiche. Riv. Geogr. Ital. 1979, 86, 338-436.

9. Del Prete, M.; Valentini, G. Le caratteristiche geotecniche delle Argille Azzurre dell'Italia sud-orientale in relazione alle differenti situazioni stratigrafiche e tettoniche. Bari Geol. Appl. Idrogeol. 1971, 6, 197-215.

10. Dramis, F.; Gentili, B.; Coltorti, M.; Cherubini, C. Piano di Gestione. Riserva dei Calanchi di Montalbano Provincia di Matera 60. Osservazioni geomorfologiche sui calanchi. Geogr. Fis. Din. Quat. 1982, 5, $38-45$.

11. Levi, C. Cristo si è fermato a Eboli; Einaudi: Turin, Italy, 1945.

12. Canale, A. Il fascino e il segreto della Basilicata. Available online: http:/ / www.ilportaledelsud.org/basilicata. htm/ (accessed on 4 August 2018).

13. Panizza, M.; Reynard, E. Géomorphosites: Définition, évaluation et cartographie. Géomorphol. Relief Process. Environ. 2005, 3, 177-180.

14. Panizza, M.; Piacente, S. Geomorphosites: A bridge between scientific research, cultural integration and artistic suggestion Geomorphological sites and geodiversity. Il Quat. Ital. J. Q. Sci. 2005, 18, 3-10.

15. Lugeri, F.R.; Amadio, V.; Cardillo, A.; Bagnaia, R.; Lugeri, N. Landscapes and Wine Production Areas: A Geomorphological Heritage. Geoheritage 2011, 3, 221-232. [CrossRef]

16. Gray, M. Geodiversity: Developing the paradigm. Proc. Geol. Assoc. 2008, 119, 287-298. [CrossRef]

17. Ruban, D.A. Quantification of geodiversity and its loss. Proc. Geol. Assoc. 2010, 121, 326-333. [CrossRef]

18. Pereira, D.I.; Pereira, P.; Brilha, J.; Santos, L. Geodiversity assessment of Parana State (Brazil): An innovative approach. Environ. Manag. 2013, 52, 541-552. [CrossRef] [PubMed]

19. Brilha, J. Geoconservation and protected areas. Environ. Conserv. 2002, 29, 273-276. [CrossRef]

20. Wimbledon, W.A.P. Geosites-A new conservation initiative. Episodes 1996, 19, 87-88.

21. Legge Quadro Sulle Aree Protette. Available online: http://www.gazzettaufficiale.it/eli/id/1991/12/13/ 091G0441/sg (accessed on 4 May 2018). 
22. Institute for Environmental Protection and Research (ISPRA). Available online: http:/ / www.isprambiente. gov.it/it/progetti/suolo-e-territorio-1/tutela-del-patrimonio-geologico-parchi-geominerari-geoparchi-egeositi/il-censimento-nazionale-dei-geositi (accessed on 4 April 2018).

23. Dowling, R.; Newsome, D. Geotourism; Elsevier Butterworth Heinemann: Oxford, UK, 2006.

24. Dowling, R.K.; Newsome, D. (Eds.) Geotourism: The Tourism of Geology and Landscape; Edith Cowan University; Murdoch University: Perth, Australia, 2010.

25. Allan, M. Geotourism: Toward a Better Understanding of Motivations for a Geotourism Experience: A SelfDetermination Theory Perspective; LAP Lambert Academic Publishing: Saarbrucken, Germany, 2012.

26. Ruban, A. Geotourism-A geographical review of the literature. Tour. Manag. Perspect. 2015, 15, 1-15. [CrossRef]

27. Naveh, Z.; Lieberman, A.S. Landscape Ecology Theory and Application; Series on Environmental Management; Springer: New York, NY, USA, 1994.

28. Forman, R.T.T.; Godron, M. Landscape Ecology; Wiley: New York, NY, USA, 1986; p. 620.

29. Amadio, V. Analisi di Sistemi e Progetti di Paesaggio; Angeli: Milano, Italy, 2003; p. 23.

30. Carta Della Natura Alla Scala 1:250.000: Metodologie di Realizzazione; Manuali e Linee Guida 17/2003; Agenzia per la protezione dell'ambiente e per i servizi tecnici (APAT): Roma, Italy, 2003.

31. Gray, M. Geodiversity: The origin and evolution of a paradigm. In The History of Geoconservation; Burek, C.D., Prosser, C.D., Eds.; Special Publication 300; Geological Society: London, UK, 2008; pp. 31-36.

32. Kozlowski, S. Geodiversity: The concept and scope of geodiversity. Prz. Geol. 2004, 52, 833-837.

33. Prosser, C.; Díaz-Martínez, E.; Larwood, J. The Conservation of Geosites Principles and Practice. In Geoheritage; Elsevier: New York, NY, USA, 2018; Chapter 11.

34. Piacente, S. Geosites and Geodiversity for a cultural approach to Geology. II Quat. Ital. J. Quat. Sci. 2005, 18, 11-14.

35. Brilha, J. Inventory and Quantitative Assessment of Geosites and Geodiversity Sites: A Review. Geoheritage 2016, 8, 119-134. [CrossRef]

36. Gray, M. Geodiversity: Valuing and Conserving Abiotic Nature; John Wiley \& Sons: Chichester, UK, 2004.

37. Amadio, V.; Amadei, M.; Bagnaia, R.; Di Bucci, D.; Laureti, L.; Lisi, A.; Lugeri, F.R.; Lugeri, N. The role of Geomorphology in Landscape Ecology: The Landscape Unit Map of Italy, Scale 1:250,000 ("Carta della Natura" Project). In Applied Geomorphology: Theory and Practice; Allison, R.J., Ed.; Wiley: London, UK, 2002; pp. 265-282.

38. GeoViewer. Available online: http:/ / www.geoviewer.isprambiente.it (accessed on 11 February 2018).

39. McKinster, J.; Trautmann, N.; Barnett, M. Teaching Science and Investigating Environmental Issues with Geospatial Technology: Designing Effective Professional Development for Teachers; Springer Science \& Business Media: Berlin, Germany, 2013; p. 353.

40. Sieber, R. Public Participation Geographic Information Systems: A Literature Review and Framework. Ann. Assoc. Am. Geogr. 2006, 96, 491-507. [CrossRef]

41. Ciaranfi, N.; Gallicchio, S.; Girone, A.; Maiorano, P.; Marino, M. Proposta di un percorso geologico culturale tra i calanchi del geosito di Montalbano Jonico (Basilicata). Geol. dell'Ambiente 2010, (Suppl. 2/201), $214-226$.

42. Farabollini, P.; Miccadei, E. The geomorpho-touristic landscapes of Marche-Abruzzi region: Perspective for geo-excursionism between geomorphological emergency, geomorphosites and geoparks. Geoital. Rimini 2009, 3, 9-11.

43. Farabollini, P.; Scalella, G. Geotouristic routes in Monte Ascensione and badlands district. Mem. Descr. Carta Geol. d'It. 2014, 102, 57-72.

44. Lugeri, F.R.; Farabollini, P.; Amadio, V.; Greco, R. Unconventional Approach for Prevention of Environmental and Related Social Risks: A Geoethic Mission. Geosciences 2018, 8, 54. [CrossRef]

45. Lugeri, F.R.; Farabollini, P.; Greco, R.; Amadio, V. The Geological Characterization of Landscape in Major TV Series: A Suggested Approach to Involve the Public in the Geological Heritage Promotion. Sustainability 2015, 7, 4100-4119. [CrossRef]

46. Lugeri, F.R.; Farabollini, P.; Graziano, G.; Amadio, V. GEOHERITAGE: Nature and culture in a landscape approach. Eur. Geol. 2012, 34, 23-28.

47. Ghazia, J.M.; Ólafsdóttir, R.; Tongkul, F.; Ghazi, J.M. Geological Features for Geotourism in the Western Part of Sahand Volcano; NW Iran. Geoheritage 2013, 5, 23-34. [CrossRef] 
48. Gregori, L. "I Paesaggi del Vino" di Goethe. Winescapes e Geositi in Umbria. In I Paesaggi del vino 5. Il Paesaggio tra Reale e Virtuale; Università di Perugia: Perugia, Italy, 2009; pp. 29-30.

49. Ólafsdóttir, R.; Runnström, M.C. A GIS Approach to Evaluating Ecological Sensitivity for Tourism Development in Fragile Environments. A case study from SE Iceland. Scand. J. Hosp. Tour. 2009, 9, 1-17. [CrossRef] 